\title{
Perfil del profesional nutricionista requerido por las instituciones empleadoras en la ciudad de Lima
}

\author{
C. Villarreal, I. Arteaga, A. Higa, M. Quintana, S. Espinoza \\ Facultad de Medicina, UNMSM
}

Objetivos: Comprobar si las competencias profesionales, caracteristicas y cualidades del nutricionista egresado de la EAP Nutrición están de acuerdo a las expectativas de las instituciones empleadoras.

Diseño: Estudio descriptivo, transversal, observacional.

Institución: Facultad de Medicina, UNMSM.

Participantes: Directivos de empleadoras de nutricionistas.

Intervenciones: A 28 instituciones empleadoras de nutricionistas egresados de la UNMSM, se aplicó una encuesta con el listado de competencias del plan curricular para cada área de desempeño profesional: Nutrición Clínica, Nutrición Pública, Servicios de Alimentación Colectiva y Deporte.

Principales medidas de resultados: Competencias, características y cualidades, según áreas de desempeño profesional.

Resultados: Todas las competencias en las diferentes áreas del listado fueron consideradas importantes para el desempeño del nutricionista. Además los encuestados recomendaron otras competencias necesarias para su institución. Respecto a las características y cualidades, no manifestaron preferencia por determinada edad o sexo, pero sí coincidieron en destacar la presentación y el trato personal, así como la iniciativa, en la práctica de la profesión.

Conclusiones: El perfil de competencias del profesional definido por la Escuela de Nutrición para sus egresados estuvo de acuerdo a las expectativas de las instituciones empleadoras. Sin embargo, requeriría reforzar algunos aspectos en cada una de las áreas de desempeño, así como en la formación de valores y liderazgo.

Palabras clave: Perfil profesional, competencias del nutricionista.

\section{Expectativas y prioridades laborales de los estudiantes de la Facultad de Medicina en una universidad peruana}

\author{
Hernán Sanabria, Carolina Tarqui, Eduardo Zárate
}

Universidad Nacional Mayor de San Marcos

Objetivos: Determinar las expectativas y prioridades laborales de los estudiantes de la Facultad de Medicina de una universidad peruana.

Diseño: Estudio observacional, descriptivo y exploratorio.

Institución: Universidad Nacional Mayor de San Marcos.

Participantes: Alumnos de preinternado.

Intervenciones: Se incluyó 278 alumnos de preinternado, matriculados en la Facultad de Medicina Humana, que voluntariamente aceptaron participar en el estudio. El muestreo fue por conveniencia, y se aplicó un cuestionario ad hoc. Se realizó juicio de expertos y estudio piloto. Se calculó promedios, desviación estándar y frecuencias absolutas y relativas.

Principales medidas de resultados: Porcentajes y promedios, con desviación estándar.

Resultados: A 50\% de los estudiantes le gustaría desarrollarse en el área asistencial; $14,5 \%$ tenía la intención de trabajar en el nivel primario de salud; en $87,1 \%$, estudiar en la UNMSM es una fortaleza para su vida profesional; $57,6 \%$ deseaba estudios de postgrado, $58,6 \%$ tenía intención de trabajar en Lima, $21,9 \%$ en provincias y $16,2 \%$ en el extranjero.

Conclusiones: La mayoría de los estudiantes tuvo la intención de laborar en Lima y una baja proporción de trabajar en el nivel primario de salud.

Palabras clave: Recursos humanos, salud, estudiantes, universidades, Perú. 